\title{
Thermal Behaviour Analysis and Cost-Saving Opportunities of PCM-Integrated Terracotta Brick Buildings
}

\author{
A. Chelliah $\mathbb{D}$, ${ }^{1}$ Shaik Saboor $\mathbb{D}^{1},{ }^{1}$ Aritra Ghosh $\mathbb{D},{ }^{2,3,4}$ and Karolos J. Kontoleon $\mathbb{D}^{5}$ \\ ${ }^{1}$ School of Mechanical Engineering, Vellore Institute of Technology, Vellore - 632014, Tamil Nadu, India \\ ${ }^{2}$ Environment and Sustainability Institute, University of Exeter, Penryn, Cornwall TR10 9FE, UK \\ ${ }^{3}$ College of Engineering, Mathematics and Physical Sciences, Renewable Energy, University of Exeter, Penryn, \\ Cornwall TR10 9FE, UK \\ ${ }^{4}$ Renewable Energy, Stella Turk Building, University of Exeter, Penryn, Cornwall TR10 9FE, UK \\ ${ }^{5}$ Department of Civil Engineering, Aristotle University of Thessaloniki, University Campus, Gr 54124 Thessaloniki, Greece
}

Correspondence should be addressed to Shaik Saboor; saboor.nitk@gmail.com

Received 17 October 2020; Revised 3 January 2021; Accepted 23 January 2021; Published 8 February 2021

Academic Editor: Loke Foong

Copyright (c) $2021 \mathrm{~A}$. Chelliah et al. This is an open access article distributed under the Creative Commons Attribution License, which permits unrestricted use, distribution, and reproduction in any medium, provided the original work is properly cited.

Buildings contribute greatly to global energy use and consumption. The energy consumption of buildings is significant due to the integration of heating, ventilation, and cooling systems. Evidently, the utilization of phase change materials (PCMs) in building design can adequately reduce air-conditioning costs of buildings by diminishing external heat gains and losses. Moreover, the adoption of natural, eco-friendly, and cost-effective materials, such as terracotta bricks, can be valuable from an environmental point of view. This paper intends to assess the air-conditioning cost-saving potential of several PCM stuffed terracotta brick configurations. In that respect, the encapsulated PCMs were filled in the hollows of terracotta bricks. For the aims of this study, five different types of PCMs were considered, in relation to the thermophysical properties of their solid and liquid state (OM18: organic mixture, HS22: hydrated salt, OM29, OM32, and OM37). In addition, three PCM-stuffed terracotta brick configurations were examined with reference to the number of the PCM layers (PCMTB-A with one PCM layer, PCMTB-B with two PCM layers, and PCMTB-C with three PCM layers). Therefore, fifteen PCM-stuffed terracotta brick configurations were analysed numerically, related to environmental conditions that refer to two different scenarios in India (hot dry and composite climates). Results have unveiled that the OM32 PCM assemblies have shown better thermoeconomic performance compared to the other types of PCM. With respect to the most advantageous number of PCM layers, the evidence of this analysis has exposed that the PCMTB-C case has shown the highest annual air-conditioning cost-savings and the highest yearly carbon emission mitigations in both climates (Ahmedabad and Lucknow). In hot-dry climates, the PCMTB-C with OM32 PCM exhibited the highest annual air-conditioning cost-saving (\$ 74.7), the highest annual carbon emission mitigation (1.43 ton/kWh), and the moderate payback period (22.5 years) compared to the other cases. To conclude, the findings of this study suggest a suitable way to improve the decision-making process of building design, while bridging the performance gap in terms of energy efficiency and sustainability.

\section{Introduction}

Climate change and environmental degradation pose a fundamental threat to mankind. Commercial and residential buildings require a large amount of energy for heating, ventilation, and cooling systems, while they are also responsible for global warming and depletion of nonrenewable fossil fuels. In developing countries like India, the construction sector is growing rapidly due to economic progress and the growth of urban communities. Buildings constitute about $40 \%$ of global consumption of electricity, with residential buildings accounting for three-quarters of the overall energy consumption and one-third of world GHG emissions [1]. Many countries have implemented policies in place to improve energy efficiency in buildings by ameliorating the effects of climate change. People spend over $90 \%$ of their time in buildings by paying special attention to a safe, clean, and comfortable indoor environment [2]. 
The traditional means of building thermal conveniences are mechanical air-conditioning systems that are energyintensive and detrimental to the environment. In this regard, energy-efficient and environmentally friendly techniques applied to boost thermal comfort at a zero or low power consumption are passive heating and cooling systems [3, 4]. Towards this goal, terracotta bricks that are made of fired clay and have a good density which can provide a fair thermal resistance to building envelopes can be considered.

Thermal energy storage by using PCMs is a tolerable passive cooling approach to moderate heat flows through building envelopes. PCMs can absorb a significant amount of heat during the melting stage (from solid to liquid), as well as they can release the absorbed heat during the solidification stage (from liquid to solid) [5]. The ability of PCMs to provide high energy storage and their characteristics to retain thermal storage at a constant temperature make their utilization attractive for several building applications [6]. As it is widely known, PCMs are commonly categorized as organic, inorganic, and eutectic, while they should have certain characteristics such as a nontoxic and noncorrosive behaviour, a suitable thermal conductivity, a desirable latent heat, and a low cost, to attain the fundamental goal of energy efficiency sustainably [7]. Organic PCMs mostly show noncorrosive properties and congruent melting points. In addition to that, the melting point and heat of the fusion of certain organic PCMs are suitable for the cooling/heating of buildings [7]. The method to embed PCMs in the encapsulation material with a scale exceeding $5 \mathrm{~mm}$ is called macroencapsulation of PCMs, while the shape of the shell can vary (cylinders, tubes, cubes, sticks, etc.). Macroencapsulated PCMs can be used in any type, size, and dimension of the building envelope [8]. An active system with PCMs has a separate storage unit within the building to be settled, which is considered to be a demerit for the end-users. The main benefit of incorporating PCMs into building materials is that less space is required, while they can be formulated with a certain behavioural pattern at the very early stages of building construction [9]. In the literature, various shell materials having the potential for thermal energy storage at high temperatures are examined [10]. Moreover, several studies reviewed and addressed the thermal efficiency of PCM-integrated buildings as wallboard configurations assisted by the operation of the HVAC unit [11-18]. PCM wallboards in buildings have recorded an advantageous reduction of the decrement factor and increase of the time lag, as regards the propagation of a periodic heatwave [19-22]. Zhou et al. analytically investigated a ventilated Trombe wall integrated with double PCM wallboard (Inside and outside) and reported the energy storage and release efficiency of $20.2 \%$ (exterior) and $20.25 \%$ (interior) at the optimum PCM thicknesses $(8 \mathrm{~mm}$ for exterior and $28 \mathrm{~mm}$ for interior) [23].

Yoon et al. [24] experimentally studied a scaled model of a PCM integrated cool roof system and reported a better performance for the RT44 PCM assembly for a white roof in comparison with the Bio 26PCM assembly for a brown roof. Jin et al. [25] conducted the experiments and reported that the placement of the PCM pouch at a distance of $(1 / 5) L$ from the interior wall surface improves the overall thermal comfort conditions. Tunçbilek et al. [26] conducted numerical simulation on PCM-integrated office building and reported energy savings of up to $12.8 \%$ with PCM of $23 \mathrm{~mm}$ thickness located at the inner side of the wall. A review of the use of macroencapsulated PCMs for various building enclosures was presented in detail [27]. The thermal efficiency of a concrete wall integrated with PCMs was analysed numerically by Lie et al. As seen, the incorporation of a $10 \mathrm{~mm}$ thick PCM layer in a vertical wall leads to approximately $20-30 \%$ reduction of heat gains through buildings located in hot tropical climates [28]. The thermal performance of the PCM integrated brick was numerically investigated by Tunçbilek et al. [29], and they reported the optimum PCM's melting temperatures as $18^{\circ} \mathrm{C}$ and $26^{\circ} \mathrm{C}$, respectively, for winter and summer seasons.

The PCM thermal shield position of a building model was experimentally investigated and optimized by Lee et al. The results exposed the optimal location of PCM layers from the inner surface for various wall orientations [30]. The PCM impact on building energy consumption was simulated for one whole year in five different cities in China by using Energy Plus. Results have underlined a significant energy saving in buildings integrated with PCMs [31]. PCM integration in buildings was also modelled and simulated in terms of energy demands, by Yun et al. [32]. Results have indicated a reduction in cooling cost by $7.48 \%$, while a six years' payback period was estimated. A building model integrated with PCMs for economic analysis was carried out with Energy Plus software by Solgi et al.; as seen, the consideration of PCMs in buildings lowered the energy requirements for certain thermal comfort requirements, although it is not rational from an economical point of view in Iran due to the high cost of PCMs and the low costs of electricity [33].

The literature revealed that there is no significant information on the air-conditioning cost-saving potential, carbon emission mitigation, and payback period by adopting PCM stuffed terracotta bricks in buildings. In this respect, the current study aims to analyze numerically three different configurations of PCM stuffed terracotta bricks; in addition, five different types of PCMs, such as OM18, HS22, OM29, OM32, and OM37, were assessed for two different scenarios in India (hot dry and composite climates). The thermophysical properties of the assumed PCMs were measured experimentally for both solid and liquid phases. This paper explores the unsteady thermal characteristics of PCM stuffed terracotta bricks and utilizes an unsteady thermal transmittance methodology to determine the air-conditioning cost-saving within buildings. This paper also presents the mitigation of carbon emissions and the resulted payback periods for all analysed PCM stuffed terracotta brick buildings. The findings of this study help in the design of energy-efficient buildings with PCM integrated terracotta bricks.

\section{Materials and Methods}

2.1. Materials. The terracotta bricks are natural materials made of clay that shows eco-friendly behaviour. The terracotta bricks are moulded with hollows to accommodate 
PCMs, while they are fired at $1000-1200^{\circ} \mathrm{C}$ for four hours to obtain certain strength; after firing, they may obtain a compressive strength of more than $3.5 \mathrm{~N} / \mathrm{mm}^{2}$. Moreover, the terracotta bricks are lighter than the conventional bricks, showing an absorption capacity that ranges within 15-20\%. In this work, solid and hollow terracotta bricks were considered, and the hollows of the terracotta bricks were stuffed with various commercially available PCM materials. The analysed PCMs refer to HS22 (hydrated salt), OM18, OM29, OM32, and OM37 (organic mixtures) to accomplish the thermoeconomic analysis. The number of the abovementioned abbreviations illustrates the melting temperature value of each PCM.

2.2. Experimental Methodology. Thermophysical properties of terracotta bricks (in solid-state) and PCMs (in solid and liquid state) were measured by using an experimental setup as illustrated in Figure 1. The viscometer consists of cooling and heating elements to cool and heat PCMs when measuring thermal conductivity for both solid and liquid states. With stability ranging up to $\pm 0.04^{\circ} \mathrm{C}$, the system has a temperature range within $-20^{\circ} \mathrm{C}$ to $170^{\circ} \mathrm{C}$. In that respect, the appropriate temperature has been set by using the digital reading display. It consists of a bath tank that heats or cools water to an appropriate temperature. PCMs were surrounded externally, around the cup, by hot or cold water. The hot or cold water was transferred externally from the bath tank to the measuring system by a close -loop. PCMs such as OM18, HS22, and OM29 are cooled in the viscometer when calculating their thermal conductivity with a low freezing point below the atmospheric temperature at the solid-state. On the other hand, PCMs such as OM32 and OM37 are easily melted above the air temperature; due to this, PCMs were heated in the viscometer to test their liquid thermal conductivity.

The KD2 thermal property analyser (hot wire probe method) was used to measure the thermal conductivity of PCMs according to the ASTM standard [34, 35]. It consists of a cable, a probe, and a monitor to display the related data. There are two pins on the probe; the first one is used as a heating source by electric pulse, while the second one acts as a receiver. Pins have a diameter of $1.3 \mathrm{~mm}$ and a length of $3 \mathrm{~cm}$ with a distance of $6 \mathrm{~mm}$ to each other. The thermal conductivity of the solid and liquid states of the PCMs is determined by the resulted temperatures through the time domain. The thermal conductivity in the range of $0.02 \mathrm{~W} /(\mathrm{m} \cdot \mathrm{K})$ to $2.00 \mathrm{~W} /(\mathrm{m} \cdot \mathrm{K})$ can be determined with an accuracy of $\pm 10 \%$. The volumetric specific heat can also be determined in the range of 0.50 to $4.00 \mathrm{MJ} /\left(\mathrm{m}^{3} \cdot \mathrm{K}\right)$ with an accuracy of $\pm 10 \%$.

The densities of PCMs were measured with $a \pm 1 \%$ accuracy by applying a specific gravity bottle process. The volume of the PCM in the liquid state was measured in the container, and its weight was measured in the weighing machine. The differences between the weight of the bottle and the weight of the bottle with the PCM provide the PCM's weight in the liquid state. The density, the weight, and the volume of the liquid PCM were measured by the specific gravity. Nevertheless, uncertainties were noted for each

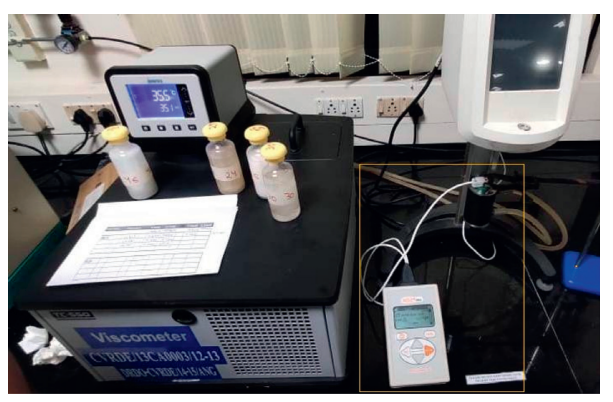

FIgURE 1: Experimental setup with viscometer and KD2 prothermal property analyser.

PCM, with reference to the evaluation of their thermal conductivity and specific heat [36]. Table 1 shows the thermal conductivity and specific heat values of the plaster, the terracotta brick, and the studied PCMs on both solid and liquid states (with uncertainties). The phase transition temperatures of PCMs were measured using differential scanning calorimetry $[37,38]$ and are presented in Table 1.

2.3. Design Methodology. The outline of analysed terracotta bricks and their corresponding dimensions is depicted in Figure 2:

(i) Figures 2(a) and 2(b) illustrate the design of a solid terracotta brick size of $0.29 \mathrm{~m}$ long $\times 0.14 \mathrm{~m}$ wide $\times 0.09 \mathrm{~m}$ high.

(ii) Figures 2(c) and 2(d) show the design of a terracotta brick integrated with one PCM layer (PCMTB-A).

(iii) Figures 2(e) and 2(f) show the design of a terracotta brick integrated with two PCM layers (PCMTB-B).

(iv) Figures $2(\mathrm{~g})$ and $2(\mathrm{~h})$ show the design of a terracotta brick integrated with three PCM layers (PCMTB-C).

Each PCM layer within the terracotta brick is of the size $0.29 \mathrm{~m} \times 0.06 \mathrm{~m} \times 0.01 \mathrm{~m}$. Figure $3(\mathrm{a})$ shows the cube-shaped building model $(3.00 \mathrm{~m} \times 3.00 \mathrm{~m} \times 3.00 \mathrm{~m})$ considered for the objectives of this work. The terracotta bricks are laid in and bound together with plaster; accordingly, the bond between bricks and plaster is equal to $0.0125 \mathrm{~m}$. Furthermore, the thickness of the conventional reinforced cement concrete (RCC) roof is $0.15 \mathrm{~m}$, while as seen in Figure 3(b), both sides of its structure are covered with a plaster of $0.0125 \mathrm{~m}$.

2.4. Analytical Methodology. As it is well known, the cooling loads through building envelopes can be diminished by adjusting their thermal mass, as well as by increasing their thermal resistance. PCM stuffed terracotta bricks can significantly improve the thermal mass and thermal resistance of building structure.

The steady-state transmittance $\left(U_{s}\right)$ relies exclusively on the thermal conductivity of the involved materials. Therefore, a steady-state transmittance signifies only the thermal resistance. On the contrary, an unsteady-state transmittance 
TABLE 1: Thermophysical properties of studied building materials.

\begin{tabular}{|c|c|c|c|c|c|c|c|c|c|}
\hline \multirow[b]{2}{*}{ PCM } & \multirow{2}{*}{$\begin{array}{c}\text { Phase } \\
\text { transition } \\
\text { range }\end{array}$} & \multirow{2}{*}{$\begin{array}{l}\text { Solid } \\
\text { PCM } \\
\text { temp. } \\
\left({ }^{\circ} \mathrm{C}\right)\end{array}$} & \multicolumn{2}{|c|}{$k(\mathrm{~W} /(\mathrm{m} \cdot \mathrm{K}))$} & \multirow{2}{*}{$\begin{array}{l}\text { Liquid PCM temp. } \\
\left({ }^{\circ} \mathrm{C}\right)\end{array}$} & \multicolumn{2}{|c|}{$\mathrm{Cp}(\mathrm{kJ} /(\mathrm{kg} \cdot \mathrm{K}))$} & \multicolumn{2}{|c|}{$\rho\left(\mathrm{kg} / \mathrm{m}^{3}\right)$} \\
\hline & & & Solid & Liquid & & Solid & Liquid & Solid & Liquid \\
\hline OM18 & $14-20$ & 14 & $0.182 \pm 0.002$ & $0.176 \pm 0.003$ & 28 & $2.93 \pm 0.02$ & $2.70 \pm 0.02$ & $907 \pm 6$ & $871 \pm 5$ \\
\hline HS22 & $18-28$ & 15 & $1.14 \pm 0.001$ & $0.57 \pm 0.005$ & 28 & $2.28 \pm 0.06$ & $2.53 \pm 0.03$ & $1651 \pm 3$ & $1556 \pm 4$ \\
\hline OM29 & $24-33$ & 20 & $0.293 \pm 0.004$ & $0.173 \pm 0.007$ & 33 & $2.33 \pm 0.02$ & $2.72 \pm 0.01$ & $976 \pm 5$ & $880 \pm 3$ \\
\hline OM32 & $28-38$ & 28 & $0.219 \pm 0.002$ & $0.145 \pm 0.002$ & 40 & $3.13 \pm 0.01$ & $2.82 \pm 0.02$ & $926 \pm 4$ & $875 \pm 2$ \\
\hline OM37 & $33-40$ & 33 & $0.17 \pm 0.003$ & $0.14 \pm 0.002$ & 45 & $2.56 \pm 0.04$ & $2.63 \pm 0.02$ & $974 \pm 2$ & $865 \pm 3$ \\
\hline Plaster & & - & $0.721 \pm 0.005$ & - & - & $1.76 \pm 0.04$ & - & $840 \pm 3$ & - \\
\hline $\begin{array}{l}\text { Terracotta } \\
\text { brick }\end{array}$ & & - & $0.62 \pm 0.004$ & - & - & $0.816 \pm 0.04$ & - & $1950 \pm 5$ & - \\
\hline
\end{tabular}

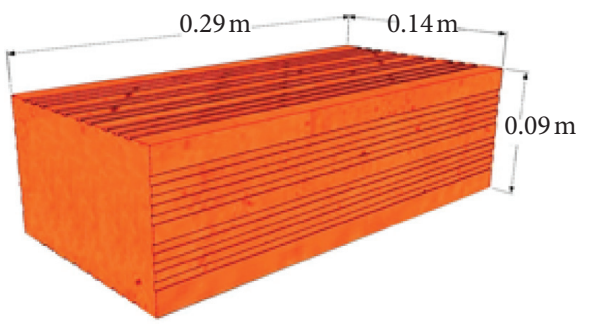

(a)

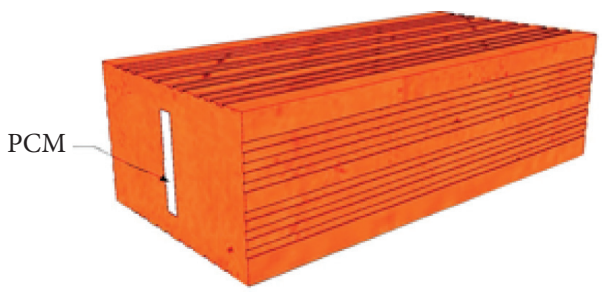

(c)

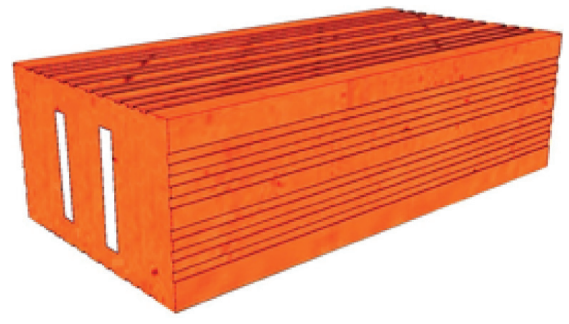

(e)

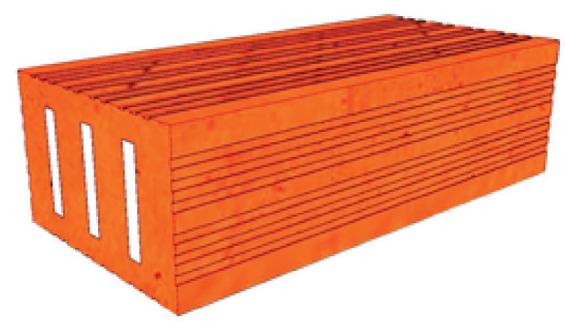

(g)

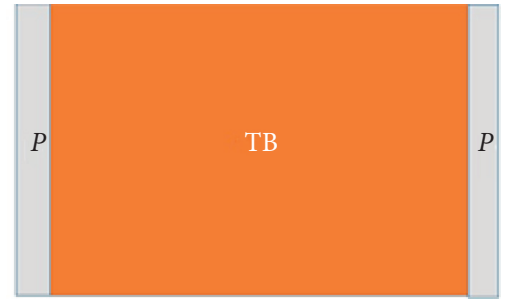

$0.0125 P+0.14 \mathrm{~TB}+0.125 P$

(b)

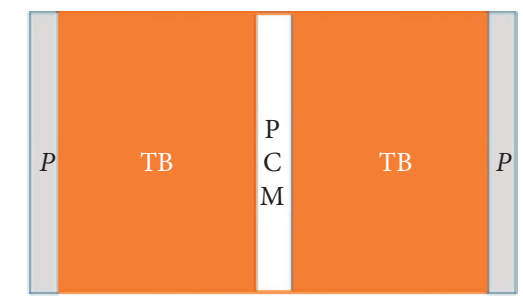

$0.125 P+0.065 \mathrm{~TB}+0.01 \mathrm{PCM}+0.065 \mathrm{~TB}+0.0125 P$

(d)

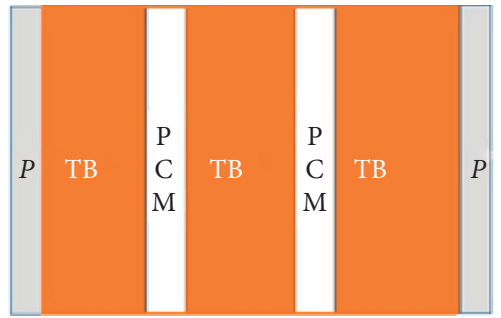

$0.0125 P+0.04 \mathrm{~TB}+0.01 \mathrm{PCM}+0.04 \mathrm{~TB}+$ $0.01 \mathrm{PCM}+0.04 \mathrm{~TB}+0.0125 P$

(f)

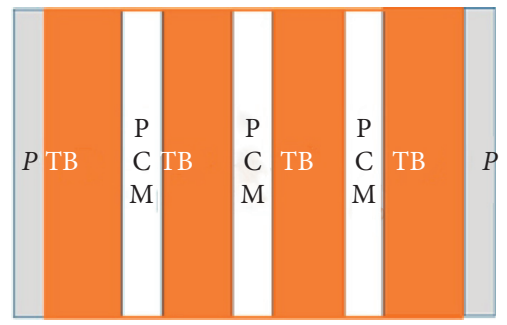

$0.125 P+0.028 \mathrm{~TB}+0.01 \mathrm{PCM}+0.027+0.01 \mathrm{PCM}$ $+0.027 \mathrm{~TB}+0.01 \mathrm{PCM}+0.028 \mathrm{~TB}+0.0125 \mathrm{P}$

(h)

FIGURE 2: Outline of assumed terracotta brick geometries: (a)-(b) solid terracotta brick; (c)-(d) terracotta brick with one PCM layer; (e)-(f) terracotta brick with two PCM layers; (g)-(h) terracotta brick with three PCM layers. 


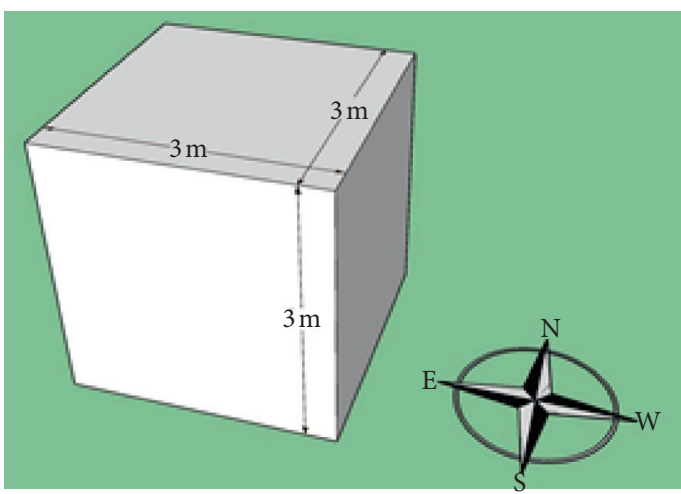

(a)

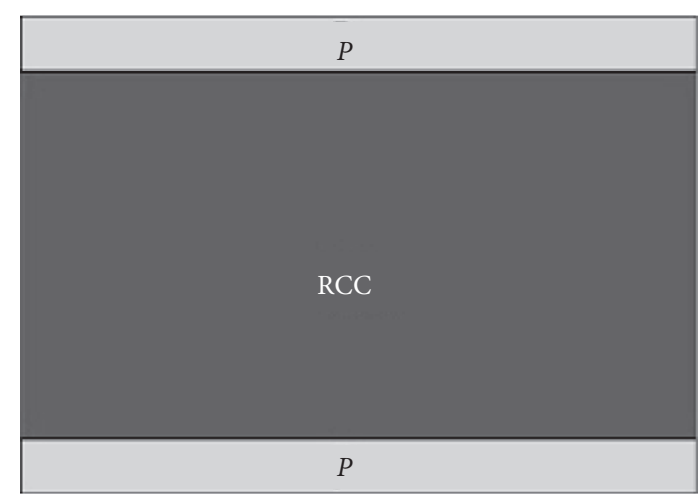

(b)

FIgURE 3: (a) Cube-shaped building model; (b) RCC roof configuration.

$\left(U_{t}\right)$ is the measure of both the thermal resistance and the thermal mass of building elements (walls, slabs, roofs, etc.), as it simultaneously takes into account the thermal conductivity, the specific heat capacity, and the density, under periodic thermal conditions. A lower unsteady-state thermal transmittance value signifies a higher thermal resistance and thermal mass [39-43]. The steady-state thermal transmittance $U_{s}$ indicates the heat transfer rate through a building configuration. A lower value of steady-state transmittance implies better thermal resistance of its assembly. It is given by the following equation:

$$
U_{\mathrm{TB}+\mathrm{PCMs}}=\left(\frac{1}{h_{o}}+\frac{X_{p}}{k_{p}}+\frac{X_{\mathrm{tb}}}{k_{\mathrm{cb}}}+\frac{X_{\mathrm{pcm}}}{k_{\mathrm{pcm}}}+\frac{1}{h_{i}}\right)^{-1} .
$$

To determine the unsteady-state transmittance, the attenuation factor (decrement factor), and the time delay (time lag) of masonry walls settled with solid terracotta bricks and PCM stuffed terracotta bricks, a one-dimensional heat diffusion equation was solved by applying the admittance method to compute unsteady parameters:

$$
\begin{aligned}
\frac{\partial^{2} T}{\partial x^{2}} & =\frac{1}{\alpha} \cdot \frac{\partial T}{\partial \tau}, \\
{\left[\begin{array}{l}
T_{e} \\
q_{e}
\end{array}\right] } & {\left[\begin{array}{cc}
\cosh (m+i m) & \frac{(\sinh (m+i m))}{c} \\
c \sinh (m+i m) & \cosh (m+i m)
\end{array}\right]\left[\begin{array}{l}
\mathrm{T}_{i} \\
q_{i}
\end{array}\right], }
\end{aligned}
$$

where $T_{e}$ is the cyclic temperature, $q_{e}$ is the cyclic heat flux, $\alpha$ indicates the thermal diffusivity $\left(\alpha=k / \rho C_{p}\right)$, and $m$ signifies the cyclic thickness $(m=x \cdot z)$. In addition, $x$ specifies the element thickness, while $z$ refers to the finite thickness of the element $\left(z=\sqrt{\rho c_{p} / k n}\right)$, and $n$ is the cyclic period.

The characteristic admittance of an element is derived by $(c)=\sqrt{j} 2 \pi k \rho c_{p} / n$ and therefore it is

$$
\begin{aligned}
{\left[\begin{array}{cc}
f_{1} & f_{2} \\
f_{3} & f_{1}
\end{array}\right] } & =\left[\begin{array}{cc}
b_{1}+i b_{2} & \frac{\left(b_{3}+i b_{4}\right)}{c} \\
c\left(-b_{4}+i b_{3}\right) & b_{1}+i b_{2}
\end{array}\right], \\
b_{1} & =\cosh m \cos m, \\
b_{2} & =\sinh m \sin m, \\
b_{3} & =(\cosh m \sin m+\sinh n \cos m)\left(\frac{1}{\sqrt{2}}\right), \\
b_{4} & =(\cosh m \sin m+\sinh m \cos m)\left(\frac{1}{\sqrt{2}}\right) .
\end{aligned}
$$

Moreover, it is

The matrices for internal and external surface resistances are given by

$$
r_{s t}=\left[\begin{array}{cc}
1 & h_{i}^{-1} \\
0 & 1
\end{array}\right] \cdot r_{s o}=\left[\begin{array}{cc}
1 & h_{o}^{-1} \\
0 & 1
\end{array}\right] .
$$

The transmission matrix for conventional walls with convection resistance is given by

$$
\left[\begin{array}{l}
T_{e} \\
q_{e}
\end{array}\right]=\left[\begin{array}{cc}
1 & h_{i}^{-1} \\
0 & 1
\end{array}\right]\left[\begin{array}{ll}
m_{1} & m_{2} \\
m_{3} & m_{1}
\end{array}\right]\left[\begin{array}{ll}
n_{1} & n_{2} \\
n_{3} & n_{1}
\end{array}\right] . .\left[\begin{array}{cc}
1 & h_{o}^{-1} \\
0 & 1
\end{array}\right]\left[\begin{array}{c}
T_{i} \\
q_{i}
\end{array}\right],
$$

where $m$ and $n$ indicate different building materials:

$$
\left[\begin{array}{l}
T_{e} \\
q_{e}
\end{array}\right]=\left[\begin{array}{ll}
A_{1} & A_{2} \\
A_{3} & A_{4}
\end{array}\right]\left[\begin{array}{l}
T_{i} \\
q_{i}
\end{array}\right] \text {. }
$$

The unsteady-state transmittance $U_{t}$ is the heat flow at the inner surface when the exterior surface is exposed to a periodic temperature variation, while the room temperature is maintained at a constant temperature. It can be computed by the following equation: 


$$
U_{t}=\left|\frac{1}{A_{2}}\right| .
$$

The attenuation of the sinusoidal heatwave through the wall/roof is called the decrement factor $(f)$ or attenuation factor. It is the ratio of the unsteady transmittance to the steady transmittance:

$$
f=\frac{U_{t}}{U_{s}}
$$

Then again, the time lag $(\varphi)$ specifies the time it takes for a heatwave to propagate from the exterior to the interior surface, with respect to the temperature peaks. Its value is given by

$$
\varphi=\frac{12}{\pi} \arctan \left(\frac{i m(f)}{\operatorname{Re}(f)}\right) .
$$

A MATLAB code was developed to compute unsteadystate transmittance, decrement factor, and time lag of various masonry walls settled with terracotta bricks. In a second step, the determined unsteady-state transmittance was utilized to estimate the potential for air-conditioning costsaving and carbon emission mitigation potential, as well as the payback periods of buildings.

2.5. Cost Assessment Methodology. The temperature differences between the external environment and the constant reference temperature within the internal space of a building zone delineate the heating and cooling loads through building enclosures. The degree-hours approach is a feasible method to compute annual energy usage. The annual energy savings of building envelopes for heating and cooling can be estimated by using heating degree-hours (HDH) and cooling degree-hours $(\mathrm{CDH})$. According to the ASHRAE requirements, $18^{\circ} \mathrm{C}$ is assumed as the base temperature for both cooling and heating of buildings. ASHRAE meteorological data have been utilized for cooling and heating degree-hours in Ahmedabad $\left(23.07^{\circ} \mathrm{N} 72.63^{\circ} \mathrm{E}\right)$ and Lucknow $\left(26.75^{\circ} \mathrm{N}\right.$ $80.88^{\circ} \mathrm{E}$ ), in India [44]. Figure 4 shows the monthly cooling and heating degree-hours for both mentioned cities. Table 2 shows the elements considered for the corresponding thermoeconomic analysis. The sol-air temperature is the temperature which gives the combined effect of outdoor temperature distribution and incident solar radiation. The $\mathrm{CDH}$ can be computed by multiplying the number of cooling hours with the difference in sol-air temperature and base temperature. Similarly, $\mathrm{HDH}$ can be computed by multiplying the number of heating hours with the difference in sol-air temperature and base temperature as shown in equations (10) and (11), respectively:

$$
\begin{aligned}
& \mathrm{CDH}=N_{C}\left(T_{S}-T_{b}\right), \\
& \mathrm{HDH}=N_{H}\left(T_{b}-T_{S}\right),
\end{aligned}
$$

where $N_{C}$ and $N_{H}$ are the number of cooling and heating hours, $T_{b}$ is the constant-base temperature, and $T_{s}$ is the solair temperature.
The thermoeconomic analysis can be performed to compute parameters such as cooling and heating cost savings $\left(C_{\mathrm{c}}\right.$ and $\left.C_{\mathrm{h}}\right)$, total air-conditioning cost-savings $\left(C_{\mathrm{t}}\right)$, payback period $(\mathrm{PB})$, and carbon emission mitigation (CM) [45-47]. The cooling and heating cost-saving findings provide information about the beneficial impact of inserting PCMs in terracotta bricks, compared with conventional solid terracotta brick assemblies in buildings. They can be computed by using the following equations:

$$
\begin{aligned}
C_{c} & =\left(\frac{10^{-3} \cdot C_{e} \cdot \mathrm{CDH} \cdot \Delta U_{t}^{l}}{\mathrm{COP}}\right), \\
C_{h} & =\left(\frac{10^{-3} \cdot C_{n} \cdot \mathrm{HDH} \cdot \Delta U_{t}^{s}}{\eta}\right) .
\end{aligned}
$$

Moreover, the total air-conditioning cost savings can be obtained from the following equation:

$$
C_{t}=C_{c}+C_{h} \text {. }
$$

It should be noted that $C_{h}$ and $C_{c}$ refer to the heating and cooling cost savings, while $\Delta U_{t}$ is the difference in unsteadystate thermal transmittance between the solid terracotta brick scenario and the filled with PCMs terracotta brick scenario.

Saving of electricity leads to a wanted carbon mitigation effect. This effect can be obtained from

$$
M_{c}=10^{-3}\left(\Delta U_{t}^{l} \cdot p_{1} \cdot \frac{C D H}{C O P}+\Delta U_{t}^{s} \cdot p_{2} \cdot \frac{H D H}{\eta}\right)
$$

where $p_{1}$ is the mass of carbon emission per unit energy production by the coal power plant and $p_{2}$ is the mass of carbon emission per unit energy production by natural gas.

Finally, the payback period highlights the time it takes for PCMs to recover the funds invested (the initial investment cost). It is derived by the following equation:

$$
p p=\frac{\ln \left[C_{i} \cdot(i-d) / C_{t}+t 1\right]}{\ln (1+i) /(1+d)}
$$

The inflation rate $(i)$ and discount rate $(d)$ values are considered as per the Indian scenario. This payback period method considers inflation rate and discount rates, but it does not consider the escalation rate of energy.

\section{Results and Discussion}

3.1. Unsteady Parameters of Various PCM-Stuffed Terracotta Bricks. Equations (1) and (7) are applied to assess steady and unsteady transmittances of bricks, respectively. Figure 5(a) depicts the steady and unsteady transmittances of solid and terracotta bricks stuffed with PCMs. From these results, it is noted that the unsteady transmittance is lower than the steady transmittance for all the studied bricks. On the other hand, the unsteady transmittance depends on the fundamental thermophysical properties of bricks, such as thermal conductivity, specific heat capacity, and density. Unsteady transmittance is the finest measure to assess the thermal mass and thermal resistance of a structure, while it allows an 


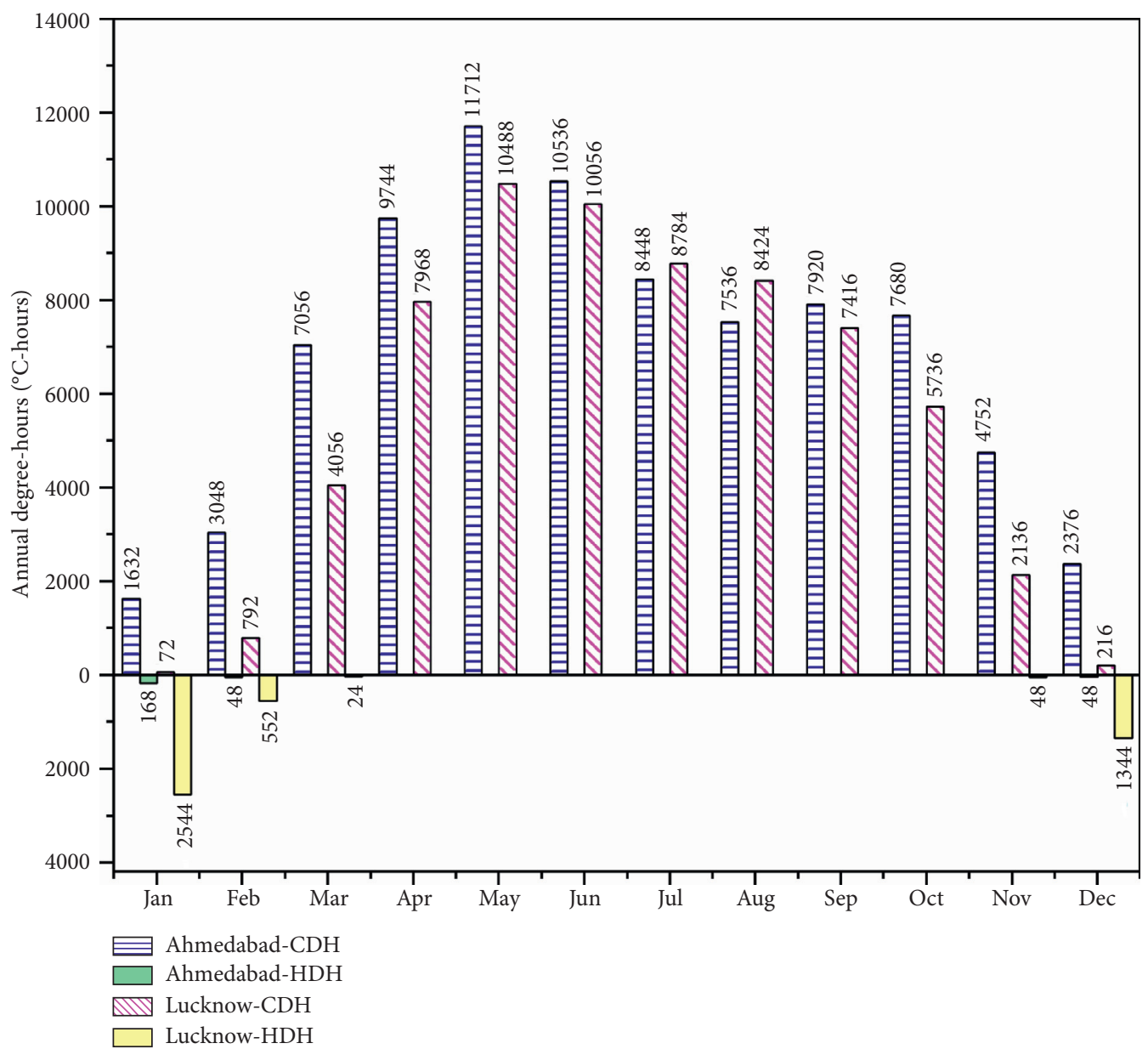

FIgURE 4: Annual cooling and heating degree-hours in Ahmedabad and Lucknow.

TABLE 2: Elements used for the thermoeconomic analysis.

\begin{tabular}{lcc}
\hline S. No. & Elements & Value \\
\hline 1 & Annual cooling degree-hours $\left(\mathrm{CDH}_{18}{ }^{\circ} \mathrm{C}\right)\left({ }^{\circ} \mathrm{C}\right.$-hours $)$ in ahmedabad and lucknow & 82440 and 6614 \\
2 & Annual heating degree-hours $\left(\mathrm{HDH}{ }_{18}{ }^{\circ} \mathrm{C}\right)\left({ }^{\circ} \mathrm{C}\right.$-hours $)$ in ahmedabad and lucknow & 264 and 4512 \\
3 & Outside and inside heat transfer coefficients $\left(h_{o}\right.$ and $\left.h_{i}\right)\left(\mathrm{W} / \mathrm{m}^{2} \mathrm{~K}\right)$ & 25.00 and 7.70 \\
4 & Coefficient of performance $(\mathrm{COP})$ & 2.50 \\
5 & Unit cost of electricity $\left(C_{e}\right)(\$ / \mathrm{kWh})$ & 0.082 \\
6 & Unit cost of natural gas $\left(C_{\mathrm{n}}\right)(\$ / \mathrm{kWh})$ & 0.014 \\
7 & Efficiency $(\eta)$ & 0.80 \\
8 & Mass of $\mathrm{CO}_{2}$ emission rates per unit usage of electricity $\left(p_{1}\right)(\mathrm{kg} / / \mathrm{kWh})$ & $0.98 \times 1.60$ \\
9 & Mass of $\mathrm{CO}_{2}$ emission rates per unit usage of natural gas $\left(p_{2}\right)(\mathrm{kg} / / \mathrm{kWh})$ & 0.18 \\
10 & Material cost of PCMs $\left(C_{i}\right)(\$ / \mathrm{kg}) \mathrm{C}_{\mathrm{OM} 18,} C_{\mathrm{HS} 22}, \mathrm{C}_{\mathrm{OM} 29}, \mathrm{C}_{\mathrm{OM} 32}$, and $\mathrm{C}_{\mathrm{OM} 37}$ & $3.75,1.26,4.29,2.68$, and 2.86 \\
11 & Inflation rate $(i)$ & $7.6 \%$ \\
12 & Discount rate $(d)$ & $6.6 \%$ \\
\hline
\end{tabular}

accurate calculation of air-conditioning cost-saving potential of various terracotta bricks stuffed with PCMs. As it is already mentioned, a lower value of unsteady transmittance indicates a better thermal performance of terracotta bricks (in relation to the thermal mass and the thermal resistance). PCMs in the liquid phase provide the least values of steady and unsteady transmittance compared to the solid phase, due to their superior thermophysical properties in this state.
In general, amongst all studied terracotta brick configurations (TB, PCMTB-A, PCMTB-B, and PCMTB-C), the PCMTB-C configuration has shown the best thermal behaviour due to its lowest unsteady transmittance value. Furthermore, in relation to the optimal PCM (OM18, HS22, OM29, OM32, and OM37), it is revealed that the OM32 shows the lowest steady and unsteady transmittance values. The order of preference of the examined PCMs from the 


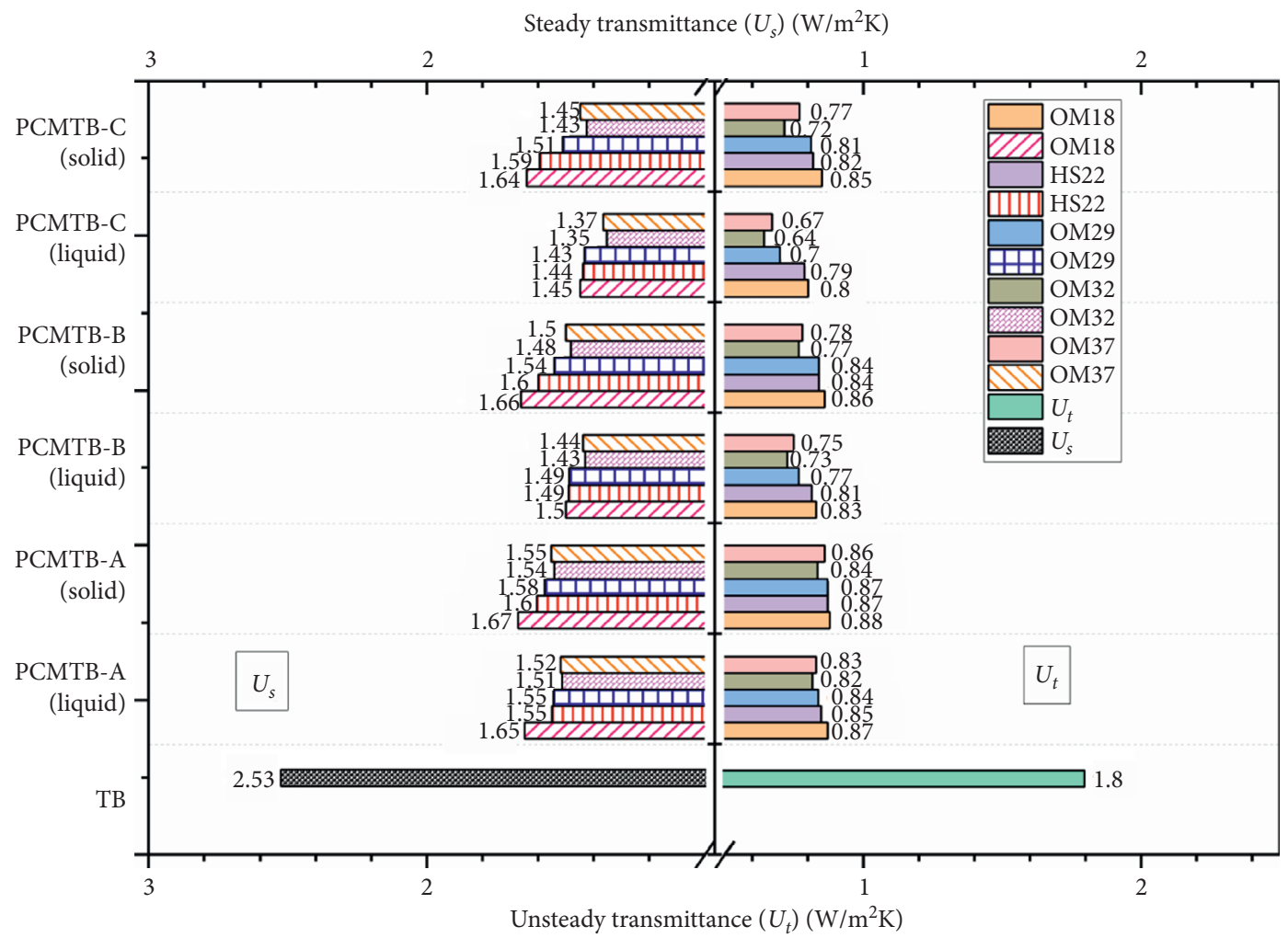

(a)

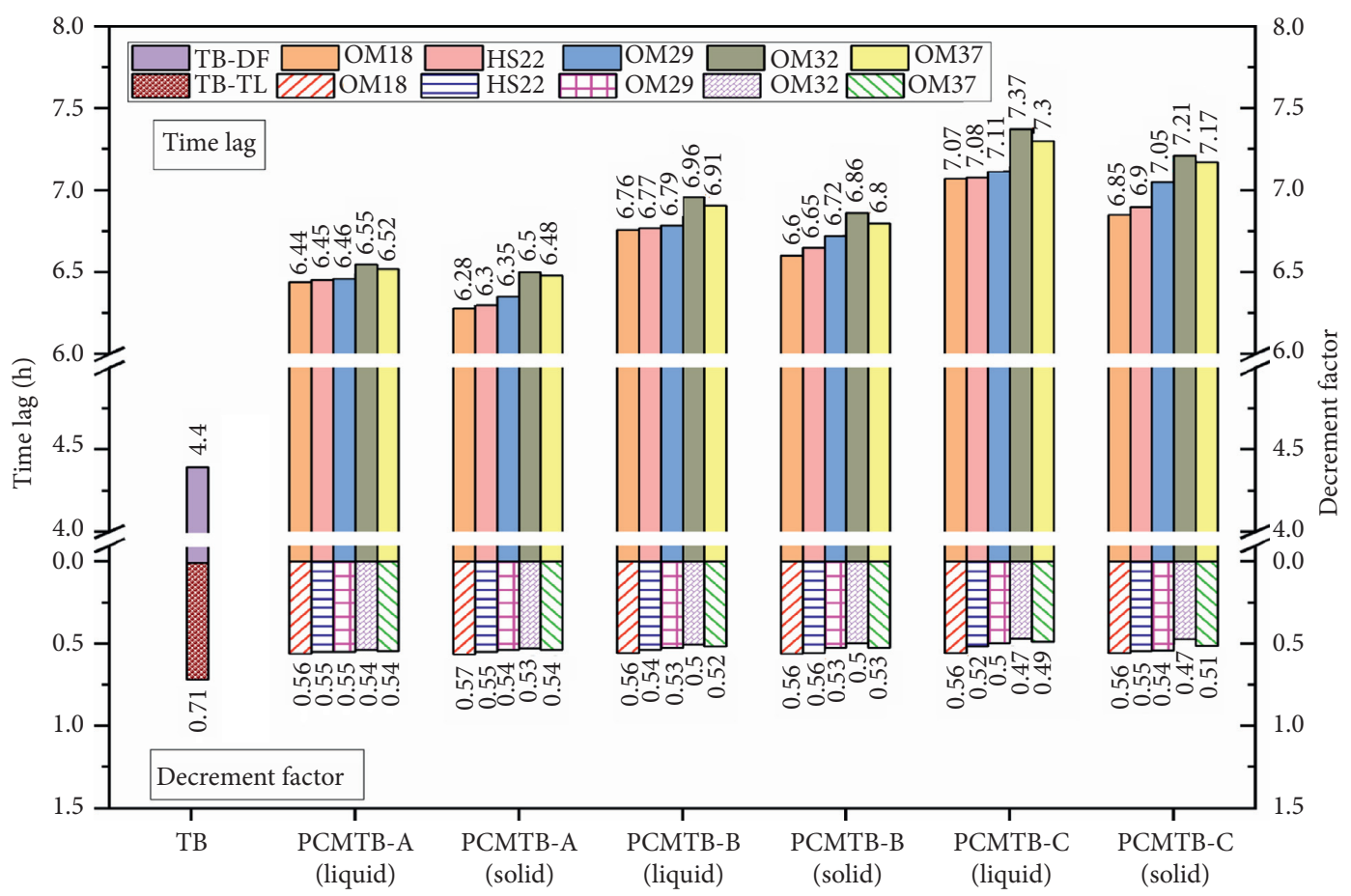

(b)

FIgUre 5: Thermal characteristics of terracotta bricks integrated with PCMs: (a) Steady and unsteady transmittance variations; (b) decrement factor and time lag variations. 
least steady and unsteady transmittance to the highest steady and unsteady transmittance is OM32<OM37<OM29< HS22 < OM18.

The decrease of the decrement factor, as well as the increase of the time lag by selecting terracotta brick, can affect substantially the indoor thermal comfort conditions in buildings; in that respect, temperature peaks due to the heatwave can be attenuated and shifted from peak hours to nonpeak hours. To assess the decrement factor and time lag values, one can apply equations (8) and (9), respectively. To improve the thermal performance of terracotta brick, the attenuation factor should be as low as possible, while the time lag should receive a high value. Figure 5(b) shows the attenuation factor and its time lag of various terracotta bricks stuffed with PCMs. PCMs in the liquid phase lead to the lowest values of the attenuation factor and the highest values of time lag, in relation to the solid phase. PCMTB-A and PCMTB-B configurations are designed with one and two layers of PCMs, respectively. The PCMTB-C is designed with three layers of PCM, and therefore the PCMTB-C offers the highest thermal mass compared to PCMTB-A and B. As it is expected, with regard to all analysed terracotta brick configurations (TB, PCMTB-A, PCMTB-B, and PCMTB-C), the PCMTB-C configuration has shown the lowest attenuation factor and the highest time lag values due to enhanced thermal mass. In addition, for the optimal PCM (OM18, HS22, OM29, OM32, and OM37), it is exposed that the OM32 shows the lowest attenuation factor and the highest time lag. To conclude, the thermal performance of all analysed terracotta brick walls stuffed with a certain PCM is clarified by $f_{\mathrm{OM} 32}<f_{\mathrm{OM} 37}<f_{\mathrm{OM} 29}<f_{\mathrm{HS} 22}<f_{\mathrm{OM} 18}$ and $\varphi_{\mathrm{OM} 32}>\varphi_{\mathrm{OM} 37}>\varphi_{\mathrm{OM} 29}>\varphi_{\mathrm{HS} 22}>\varphi_{\mathrm{OM} 18}$.

\subsection{Cooling and Heating Cost saving of Terracotta Brick} Buildings Integrated with PCMs. Equations (12) and (13) are applied to compute cooling and heating cost saving of various PCM stuffed terracotta brick buildings compared to solid terracotta brick buildings. Figures 6(a) and 6(b) illustrate the cooling and heating cost saving of various buildings, arranged with masonry walls (solid terracotta walls and terracotta walls integrated with PCMs) in Ahmedabad and Lucknow climates.

In Ahmedabad, terracotta brick wall configurations PCMTB-A stuffed with a certain PCM of OM18, HS22, OM29, OM32, and OM37 have shown a cooling cost saving of $\$ 59.92, \$ 61.34, \$ 62.00, \$ 63.34$, and \$ 62.35, respectively. Likewise, the heating cost saving is $\$ 0.1, \$ 0.1, \$ 0.1, \$ 0.11$, and $\$ 0.1$. Evidently, amongst all examined PCMs in the PCMTB-A assembly, the OM32 shows the highest cooling and heating cost saving. Furthermore, the terracotta brick wall configuration PCMTB-B stuffed with OM32 PCM shows the highest cooling and heating cost saving of $\$ 69.27$ and $\$ 0.11$, respectively. Similarly, with respect to all simulated terracotta brick wall configurations, the PCMTB-C stuffed with OM32 showed the highest cooling and heating cost saving of $\$ 74.58$ and $\$ 0.12$, respectively.

Similarly in Lucknow, terracotta brick wall configuration PCMTB-C stuffed with OM32 PCM shows the highest cooling and heating cost saving of $\$ 59.8$ and $\$ 2.04$, respectively. As seen, the cooling cost saving is more evident in Ahmedabad than in Lucknow, due to its hot-dry climatic conditions. Nevertheless, the heating cost saving is predominant in Lucknow in comparison to Ahmedabad, due to its exposed composite climate.

The most influencing thermal characteristic for enhancing cooling and heating cost savings is the unsteady transmittance of PCM integrated terracotta bricks. A lower value of unsteady transmittance contributes to higher cooling and heating cost savings. The best order of PCMs as per the highest cooling and heating cost-saving is $\mathrm{OM} 32>\mathrm{OM} 37>\mathrm{OM} 29>\mathrm{HS} 22>\mathrm{OM} 18$. The preferred order of PCM stuffed terracotta brick configuration as per the highest cooling and heating cost-saving is PCMTBC > PCMTB-B > PCMTB-A.

\subsection{Total Building Air-Conditioning Cost Saving of Terracotta} Brick Buildings Integrated with PCMs. Equation (14) is used to estimate the total building air-conditioning cost saving of terracotta brick buildings integrated with PCMs compared to conventional terracotta brick buildings. Figure 7 shows the total building air-conditioning cost saving of terracotta brick buildings stuffed with PCMs compared to solid terracotta brick buildings in Ahmedabad and Lucknow climates.

In Ahmedabad, terracotta brick wall configurations PCMTB-A, stuffed with PCMs of OM18, HS22, OM29, OM32, and OM37 have shown an overall total building airconditioning cost saving of $\$ 60.02, \$ 61.44, \$ 62.1, \$ 63.45$, and $\$ 62.63$, respectively. Amongst all PCMs in the PCMTBA, the OM32 underlines the highest total building airconditioning cost saving. The terracotta brick wall configuration PCMTB-B stuffed with OM32 PCM shows the highest total building air-conditioning cost saving of \$ 69.4 among all examined configuration in this category. In overall, among all assumed terracotta brick wall configurations stuffed with PCMs (PCMTB-A, PCMTB-B, and PCMTB-C), the PCMTB-C configuration with PCM corresponding to OM32 shows the maximum total building airconditioning cost saving of $\$ 74.7$.

In Lucknow, amongst all the examined terracotta brick wall configurations, the PCMTB-C stuffed with OM32 reveals the highest total building air-conditioning cost saving of \$ 61.9. In Ahmedabad and Lucknow, the terracotta brick wall configuration PCMTB-B with OM32 shows a $9.35 \%$ increase in total building air-conditioning cost saving compared to PCMTB-A with OM32. The terracotta brick wall configuration PCMTB-C with OM32 shows an increment of $17.73 \%$ in total building air-conditioning cost saving compared to PCMTB-A with OM32.

\subsection{Carbon Emission Mitigation Potential of Terracotta Brick} Buildings Integrated with PCMs. Equation (15) was used to determine the carbon emission mitigation of terracotta brick buildings stuffed with PCMs compared to solid terracotta brick buildings. Figure 8 shows the carbon emission 


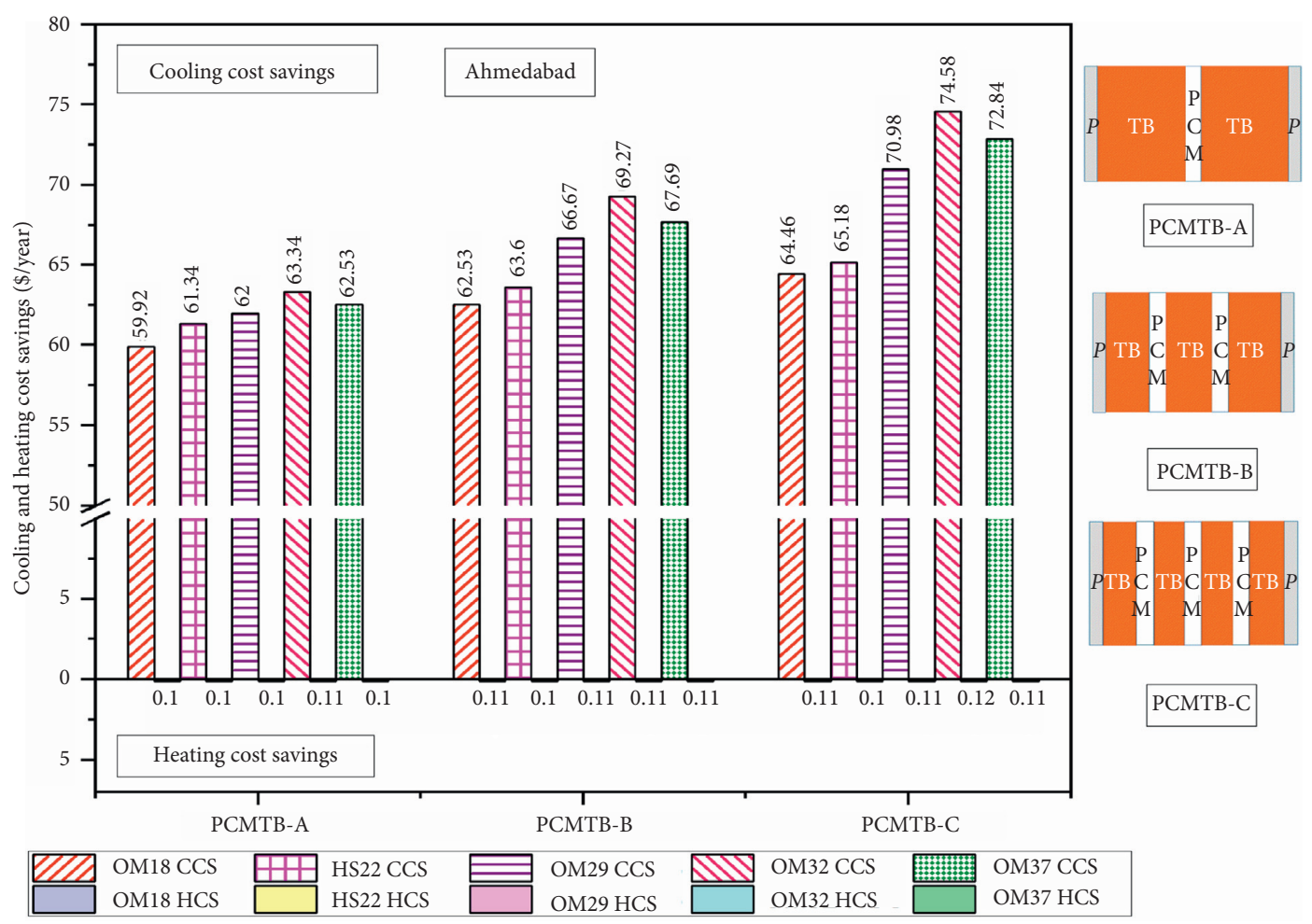

(a)

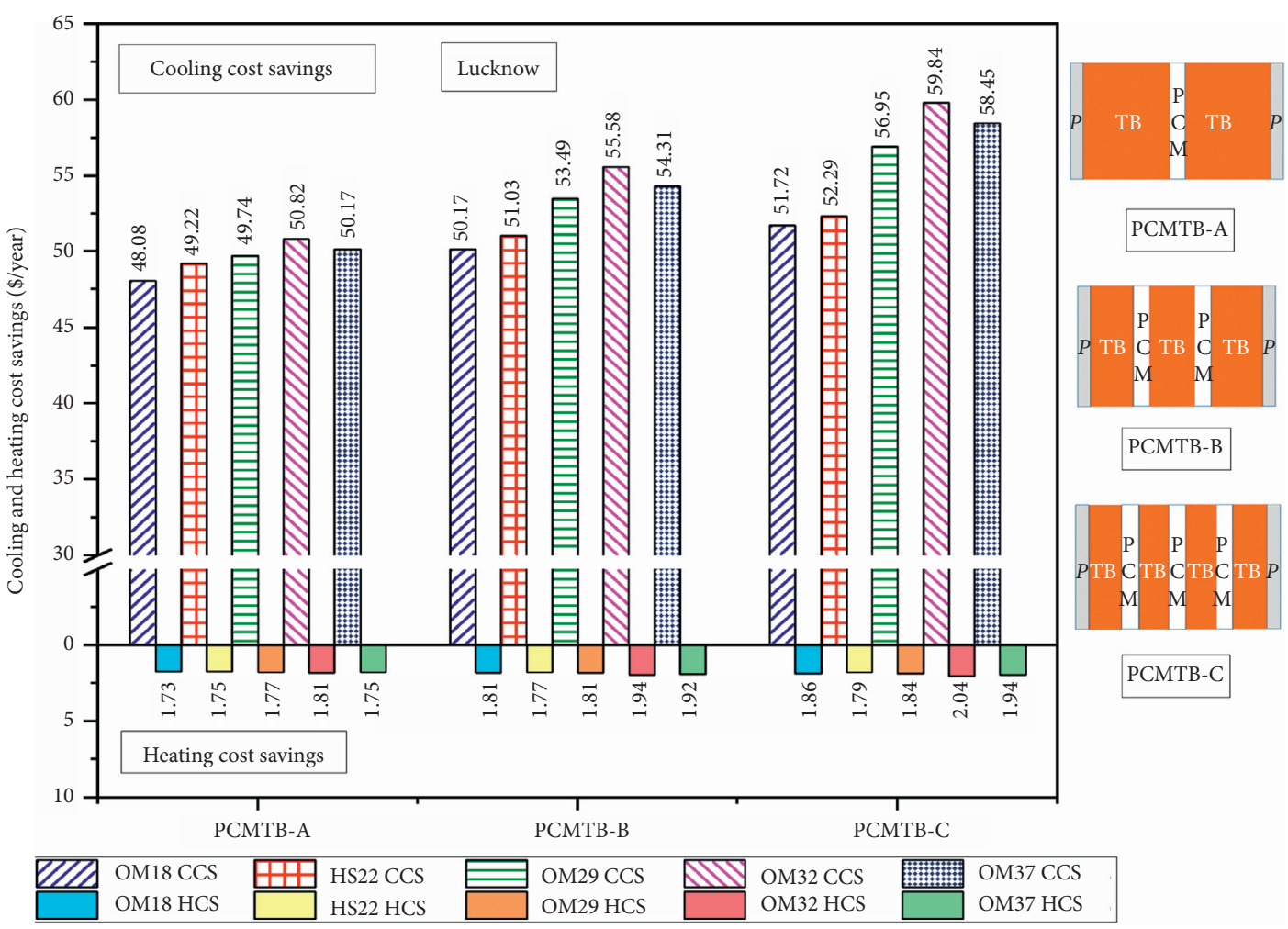

(b)

Figure 6: Annual cooling and heating cost of terracotta brick buildings integrated with PCMs: (a) Ahmedabad; (b) Lucknow. 


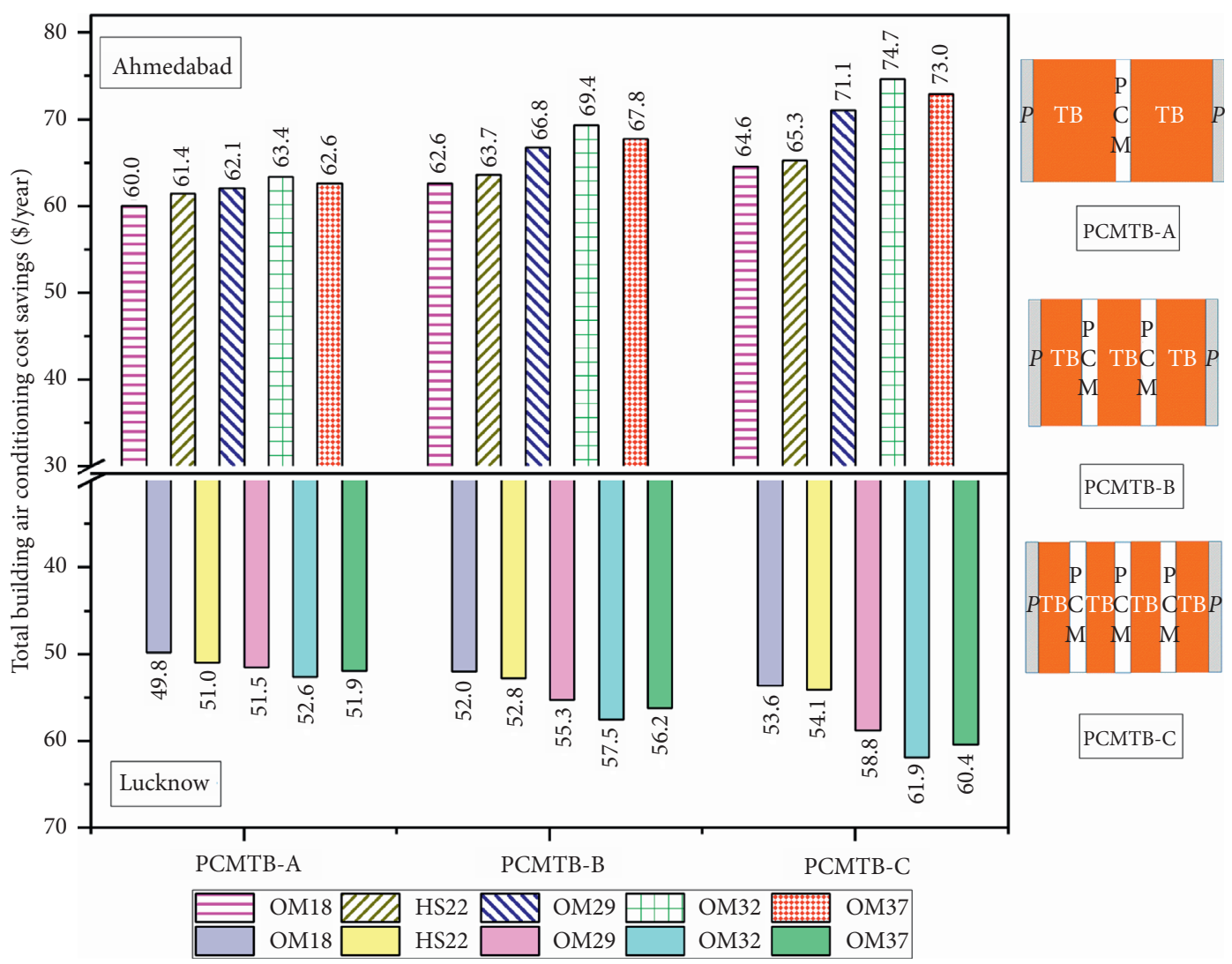

FIGURE 7: Total building air-conditioning cost saving of terracotta brick buildings integrated with PCMs in Ahmedabad and Lucknow.

mitigation potential of terracotta brick buildings integrated with PCMs in Ahmedabad and Lucknow climates.

In Ahmedabad, terracotta brick wall configurations PCMTB-A stuffed with PCMs of OM18, HS22, OM29, OM32, and OM37 have shown a carbon emission mitigation of 1.15 ton/kWh, 1.17 ton/kWh, 1.19 ton/kWh, 1.21 ton/ $\mathrm{kWh}$, and 1.20 ton/kWh, respectively. Amongst all PCMs in the PCMTB-A assembly, the OM32 shows the highest carbon emission mitigation; the findings have led to a 1.21 ton/kWh mitigation effect due to the significant air-conditioning cost saving for this selection. The terracotta brick wall configuration PCMTB-B stuffed with OM32 shows the highest carbon emission mitigation of 1.33 ton/kWh among all studied PCMs. Within the framework of all analysed terracotta brick wall configurations stuffed with PCMs (PCMTB-A, PCMTB-B, and PCMTB-C), the PCMTB-C configuration with PCM corresponding to OM32 shows the highest carbon emission mitigation of $1.43 \mathrm{ton} / \mathrm{kWh}$.

Then again, in Lucknow, amongst all the terracotta brick wall configurations (PCMTB-A, PCMTB-B, and PCMTB-C) stuffed with PCMs, the PCMTB-C formations with PCM corresponding to OM32 highlights the highest carbon emission mitigation of 1.17 ton/kWh. In Ahmedabad and Lucknow, the terracotta brick wall configuration PCMTB-B with OM32 shows an increment of $9.35 \%$ in carbon emission mitigation compared to PCMTB-A with OM32. The terracotta brick wall configuration PCMTB-C with OM32 shows an increment of $17.73 \%$ in carbon emission mitigation compared to PCMTB-A with OM32.
3.5. Payback Periods of Terracotta Brick Buildings Integrated with PCMs. Equation (16) was used to calculate the payback period of terracotta brick buildings stuffed with PCMs. Figure 9 shows the payback periods of terracotta brick buildings integrated with PCMs compared to conventional terracotta bricks in Ahmedabad and Lucknow.

In Ahmedabad, terracotta brick wall configurations PCMTB-A stuffed with PCMs of OM18, HS22, OM29, OM32, and OM37 have resulted in a payback period of 13.6 years, 8.1 years, 15 years, 9.4 years, and 10 years, respectively. Amongst all PCMs in the PCMTB-A assembly, the HS22 shows the least payback period of 8.1 years followed by 9.4 years for OM32. The payback periods increase from the configurations PCMTB-A to PCMTB-C due to the increased cost of incorporating PCMs in terracotta bricks. Accordingly, the PCMTB-A and PCMTB-B configurations are more profitable from an economic point of view, while they present rational payback periods in contrast to PCMTB-C. For the lower payback periods, the following PCM materials are preferred in sequence: HS22, OM32, OM37, OM18, and OM29. The preferred sequential order of PCM is the same as material cost sequential order of PCM from low cost to high cost. The material cost of PCM is the most influential parameter in the payback period of PCM integrated terracotta bricks. From the lowest payback periods perspective, the configurations PCMTB-A and PCMTB-B are preferred over PCMTB-C.

The results of the above research findings apply to hotdry and composite climatic conditions. The research can be 


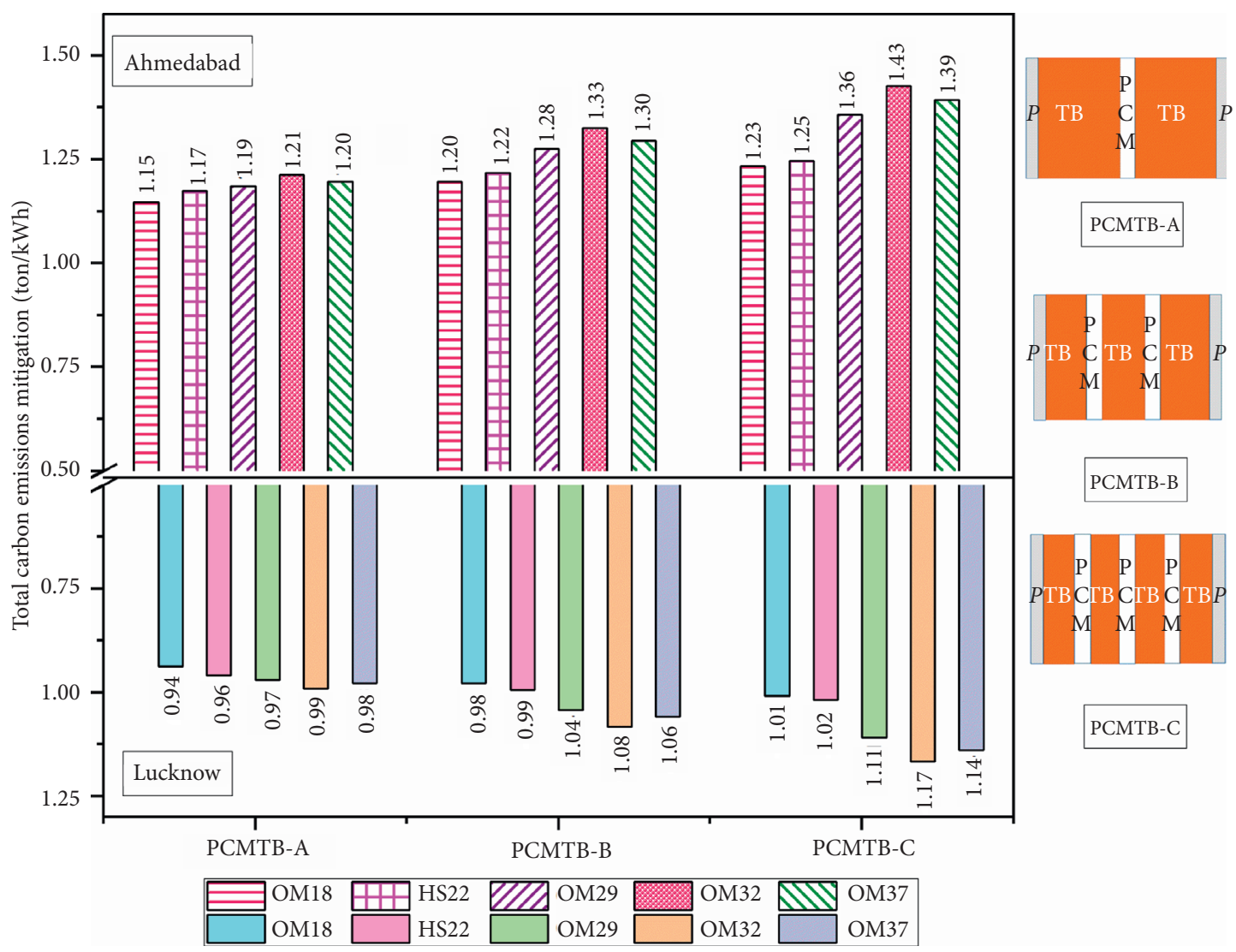

FIgURE 8: Carbon emission mitigation of terracotta brick buildings integrated with PCMs in Ahmedabad and Lucknow climates.

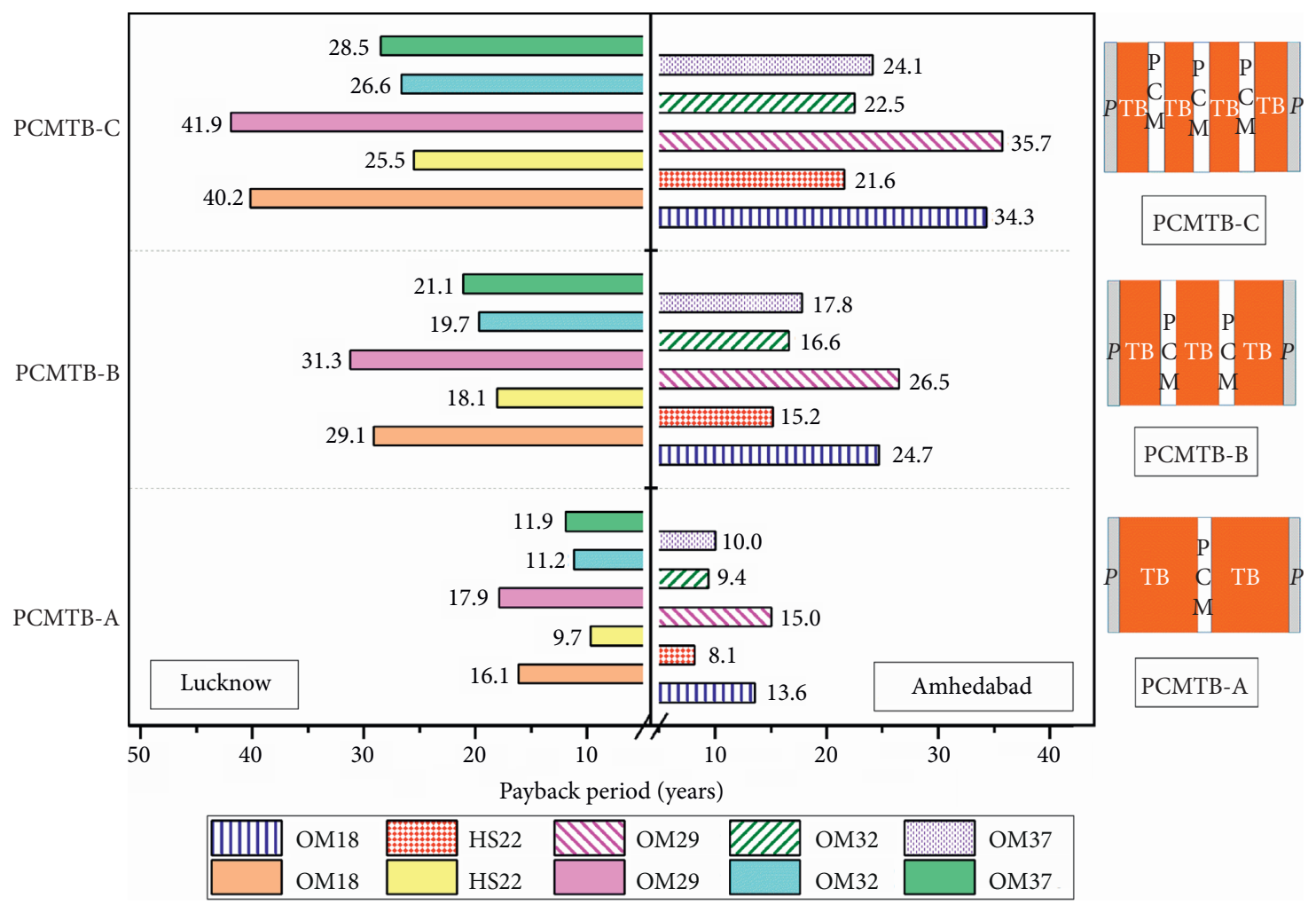

FIGURE 9: Payback periods of terracotta brick buildings integrated with PCMs in Ahmedabad and Lucknow. 
extended to other climatic regions as well. Future research can be carried out on energy-efficient building envelopes integrated with various combinations of new PCMs.

\section{Conclusions}

This work evaluates the unsteady heat transfer characteristics, air-conditioning cost-saving, carbon emission mitigation, and payback periods of various PCM stuffed terracotta bricks compared to conventional terracotta bricks. In that respect, the thermophysical properties of five different PCMs (OM18, HS22, OM29, OM32, and OM37) in both solid and liquid phases were measured. This paper presents a mathematical model to compute unsteady thermal parameters which are further utilized for computing the air-conditioning cost-saving potential of PCM stuffed terracotta brick buildings in hot-dry and composite climates of India.

(i) The buildings of PCMTB-C configuration stuffed with OM32 saves the highest yearly air-conditioning costs of $\$ 74.70$ and $\$ 61.9$, respectively, in hot-dry and composite climates of India among all three terracotta brick configurations (PCMTB-A, B, and C) with five PCMs (OM18, HS22, OM29, OM32, and OM37) studied.

(ii) The buildings of PCMTB-C configuration stuffed with OM32 saves the highest carbon emission mitigation of 1.43 ton $/ \mathrm{kWh}$ and 1.17 ton $/ \mathrm{kWh}$, respectively, in hot-dry and composite climates of India among all three terracotta brick configurations (PCMTB-A, B and C) with five PCMs (OM18, HS22, OM29, OM32, and OM37) studied.

(iii) The steady and unsteady transmittances reduce with the increase in the PCM layers in the terracotta bricks. PCMTB-C configuration stuffed with OM32 PCM gives the least steady and unsteady transmittance due to its improved thermal mass and thermal resistance compared to all studied configurations with five PCMs.

(iv) The attenuation factor reduces and time lag enhances with the increase in the PCM layers in the terracotta bricks. PCMTB-C configuration stuffed with OM32 PCM gives the least attenuation factor and the highest time lag due to its improved thermal mass and thermal resistance compared to all studied configurations with five PCMs.

(v) The best order of PCMs as per the desirable unsteady parameters, highest air-conditioning costsaving, highest carbon emission mitigation potential is OM32 > OM37 > OM29 > HS22 > OM18. The preferred order of PCM stuffed terracotta brick configuration as per the desirable unsteady parameters, highest air-conditioning cost-saving, and highest carbon emission mitigation potential is PCMTB-C > PCMTB-B > PCMTB-A.

(vi) The payback period of the building increases with the increase in the PCM layers in the terracotta brick. PCMTB-A stuffed with HS22 buildings in hot-dry climate shows the least payback period of 8.1 years among all three terracotta brick configurations (PCMTB-A, B, and C) with five PCMs (OM18, HS22, OM29, OM32, and OM37) studied. For the lower payback periods in hot-dry and composite climates, the following PCM materials are preferred in sequence: HS22, OM32, OM37, OM18, and OM29. From the lowest payback periods perspective, the configurations PCMTB-A and PCMTB-B are preferred over PCMTB-C.

(vii) It is recommended to use PCMTB-B configuration with OM32 for buildings to have desirable unsteady parameters, higher air-conditioning cost-saving, higher carbon emission mitigation potential, and acceptable payback periods. It is not advisable to go for PCMTB-C configuration due to its long payback period of about 20 years.

The results of this study are useful in designing energyconscious buildings with PCM-integrated terracotta bricks.

\section{Nomenclature}

$C_{c}: \quad$ Cooling cost saving $(\$)$

$C_{e}$ : Unit cost of electricity $(\$ / \mathrm{kWh})$

$C_{h}$ : Heating cost-saving $(\$)$

$C_{i}$ : $\quad$ Material cost of PCM $(\$ / \mathrm{kg})$

$C_{n}: \quad$ Unit cost of natural gas $(\$ / \mathrm{kWh})$

$C_{p}: \quad$ Specific heat $(\mathrm{kJ} /(\mathrm{kg} \cdot \mathrm{K}))$

$C_{t}$ : Annual air-conditioning cost-saving (\$)

$d: \quad$ Discount rate $(\%)$

$f: \quad$ Decrement factor (-)

$h$ : Heat transfer coefficient $\left(\mathrm{W} /\left(\mathrm{m}^{2} \cdot \mathrm{K}\right)\right)$

$i: \quad$ Inflation rate (\%)

$k$ : Thermal conductivity $(\mathrm{W} /(\mathrm{m} \cdot \mathrm{K}))$

$M_{c}$ : Mass of $\mathrm{CO}_{2}$ emission reduction (ton $/ \mathrm{kWh}$ )

$N_{C}$ : Number of cooling hours (h)

$N_{H}$ : Number of heating hours (h)

$p_{1}$, Mass of $\mathrm{CO}_{2}$ emission due to energy production $(\mathrm{kg} /$

$\left.p_{2}: \quad \mathrm{kWh}\right)$

$T_{b}$ : $\quad$ Base temperature $\left({ }^{\circ} \mathrm{C}\right)$

$T_{s}$ : $\quad$ Sol air temperature $\left({ }^{\circ} \mathrm{C}\right)$

$U: \quad$ Thermal transmittance $\left(\mathrm{W} /\left(\mathrm{m}^{2} \cdot \mathrm{K}\right)\right)$

$U_{t}$ : Unsteady transmittance $\left(\mathrm{W} /\left(\mathrm{m}^{2} \cdot \mathrm{K}\right)\right)$

$X: \quad$ Building material thickness $(\mathrm{m})$

\section{Greek letters}

$\alpha$ : Thermal diffusivity

$\eta$ : Efficiency of natural gas power generation

$\varphi$ : Time lag (h)

$\rho:$ Density $\left(\mathrm{kg} / \mathrm{m}^{3}\right)$

\section{Acronyms}

$\mathrm{CDH}$ : Cooling degree-hours ( ${ }^{\circ} \mathrm{C}$-hours)

COP: Coefficient of performance

$\mathrm{HDH}$ : Heating degree-hours ( ${ }^{\circ} \mathrm{C}$-hours)

HS: $\quad$ Hydrated salt 
OM: $\quad$ Organic mixture

P: $\quad$ Plaster

PP: $\quad$ Simple payback period

PCM: $\quad$ Phase change material

PCMTB: PCM-stuffed terracotta brick

TB: Terracotta brick.

\section{Data Availability}

The data used to support the findings of this study are included within the article.

\section{Disclosure}

This research received no specific grant from any funding agency (public/commercial).

\section{Conflicts of Interest}

The authors declare that they have no conflicts of interest.

\section{References}

[1] P. Nejat, F. Jomehzadeh, M. M. Taheri, M. Gohari, and M. Z. Abd. Majid, "A global review of energy consumption, $\mathrm{CO} 2$ emissions and policy in the residential sector (with an overview of the top ten CO 2 emitting countries)," Renewable and Sustainable Energy Reviews, vol. 43, pp. 843-862, 2015.

[2] R. Qi, L. Lu, and H. Yang, "Investigation on air-conditioning load profile and energy consumption of desiccant cooling system for commercial buildings in Hong Kong," Energy and Buildings, vol. 49, pp. 509-518, 2012.

[3] D. G. L. Samuel, S. M. S. Nagendra, and M. P. Maiya, "Passive alternatives to mechanical air conditioning of building: a review," Building and Environment, vol. 66, pp. 54-64, 2013.

[4] K. J. Kontoleon, "Glazing solar heat gain analysis and optimization at varying orientations and placements in aspect of distributed radiation at the interior surfaces," Applied Energy, vol. 144, pp. 152-164, 2015.

[5] V. A. A. Raj and R. Velraj, "Review on free cooling of buildings using phase change materials," Renewable and Sustainable Energy Reviews, vol. 14, no. 9, pp. 2819-2829, 2010.

[6] A. Pasupathy, R. Velraj, and R. V. Seeniraj, "Phase Change Material-based building architecture for thermal management in residential and commercial establishments," Renewable and Sustainable Energy Reviews, vol. 12, no. 1, pp. 39-64, 2008.

[7] S. S. Chandel and T. Agarwal, "Review of current state of research on energy storage, toxicity, health hazards and commercialization of Phase Changing Materials," Renewable and Sustainable Energy Reviews, vol. 67, pp. 581-596, 2017.

[8] H. Akeiber, P. Nejat, M. Z. A. Majid et al., "A review on phase change material (PCM) for sustainable passive cooling in building envelopes," Renewable and Sustainable Energy Reviews, vol. 60, pp. 1470-1497, 2016.

[9] P. K. S. Rathore and S. K. Shukla, "Potential of macroencapsulated pcm for thermal energy storage in buildings: a comprehensive review," Construction and Building Materials, vol. 225, pp. 723-744, 2019.

[10] F. Souayfane, F. Fardoun, and P.-H. Biwole, "Phase Change Materials (PCM) for cooling applications in buildings: a review," Energy and Buildings, vol. 129, pp. 396-431, 2016.
[11] R. Jacob and F. Bruno, "Review on shell materials used in the encapsulation of phase change materials for high temperature thermal energy storage," Renewable and Sustainable Energy Reviews, vol. 48, pp. 79-87, 2015.

[12] H. J. Akeiber, M. A. Wahid, H. M. Hussen, and A. T. Mohammad, "Review of development survey of phase change material models in building applications," Scientific World Journal, vol. 2014, pp. 1-11, 2014.

[13] S. R. L. da Cunha and J. L. B. de Aguiar, "Phase Change Materials and energy efficiency of buildings: a review of knowledge," Journal of Energy Storage, vol. 271260 pages, 2020.

[14] S. Mengjie, N. Fuxin, M. Ning, H. Yanxin, and D. Shiming, "Review on building energy performance improvement using Phase Change Materials," Energy and Buildings, vol. 158, pp. 776-793, 2018.

[15] A. Waqas and Z. Ud Din, "Phase change material (PCM) storage for free cooling of buildings-A review," Renewable and Sustainable Energy Reviews, vol. 18, pp. 607-625, 2013.

[16] S. Ben Romdhane, A. Amamou, R. Ben Khalifa, N. M. Saïd, Z. Younsi, and A. Jemni, "A review on thermal energy storage using phase change materials in passive building applications," Journal of Building Engineering, vol. 32, Article ID $101563,2020$.

[17] Y. Zhou, S. Zheng, Z. Liu et al., "Passive and active phase change materials integrated building energy systems with advanced machine-learning based climate-adaptive designs, intelligent operations, uncertainty-based analysis and optimisations: a state-of-the-art review," Renewable and Sustainable Energy Reviews, vol. 130, Article ID 109889, 2020.

[18] Y. Zhou, S. Zheng, and G. Zhang, "A review on cooling performance enhancement for phase change materials integrated systems-flexible design and smart control with machine learning applications," Building and Environment, vol. 174, Article ID 106786, 2020.

[19] F. Kuznik and J. Virgone, "Experimental investigation of wallboard containing phase change material: data for validation of numerical modeling," Energy and Buildings, vol. 41, no. 5, pp. 561-570, 2009.

[20] I. Mandilaras, M. Stamatiadou, D. Katsourinis, G. Zannis, and M. Founti, "Experimental thermal characterization of a mediterranean residential building with pcm gypsum board walls," Building and Environment, vol. 61, pp. 93-103, 2013.

[21] D. Mazzeo and G. Oliveti, "Parametric study and approximation of the exact analytical solution of the stefan problem in a finite PCM layer in a steady periodic regime," International Communications in Heat and Mass Transfer, vol. 84, pp. 49-65, 2017.

[22] D. Mazzeo, G. Oliveti, and N. Arcuri, "Definition of a new set of parameters for the dynamic thermal characterization of PCM layers in the presence of one or more liquid-solid interfaces," Energy and Buildings, vol. 141, pp. 379-396, 2017.

[23] Y. Zhou, C. W. F. Yu, and G. Zhang, "Study on heat-transfer mechanism of wallboards containing active phase change material and parameter optimization with ventilation," $A p$ plied Thermal Engineering, vol. 144, pp. 1091-1108, 2018.

[24] S. G. Yoon, Y. K. Yang, T. W. Kim, M. H. Chung, and J. C. Park, "Thermal performance test of a phase-changematerial cool roof system by a scaled model," Advances in Civil Engineering, vol. 2018, 11 pages, 2018.

[25] X. Jin, M. A. Medina, and X. Zhang, "On the importance of the location of pcms in building walls for enhanced thermal performance," Applied Energy, vol. 106, pp. 72-78, 2013. 
[26] E. Tunçbilek, M. Arıcı, M. Krajčík, S. Nižetić, and H. Karabay, "Thermal performance based optimization of an office wall containing PCM under intermittent cooling operation," Applied Thermal Engineering, vol. 179, Article ID 115750, 2020.

[27] Z. Liu, Z. Yu, T. Yang et al., "A review on macro-encapsulated phase change material for building envelope applications," Building and Environment, vol. 144, no. April, pp. 281-294, 2018.

[28] J. Lei, J. Yang, and E.-H. Yang, "Energy performance of building envelopes integrated with phase change materials for cooling load reduction in tropical Singapore," Applied Energy, vol. 162, pp. 207-217, 2016.

[29] E. Tunçbilek, M. Arıcı, S. Bouadila, and S. Wonorahardjo, "Seasonal and annual performance analysis of PCM-integrated building brick under the climatic conditions of Marmara region," Journal of Thermal Analysis and Calorimetry, vol. 141, no. 1, pp. 613-624, 2020.

[30] K. Lee Ok, M. A. Medina, E. Raith, and X. Sun, “Assessing the integration of a thin phase change material $(\mathrm{pcm})$ layer in a residential building wall for heat transfer reduction and management," Applied Energy, vol. 137, pp. 699-706, 2014.

[31] X. Mi, R. Liu, H. Cui, S. A. Memon, F. Xing, and Y. Lo, "Energy and economic analysis of building integrated with pcm in different cities of China," Applied Energy, vol. 175, pp. 324-336, 2016.

[32] B. Y. Yun, J. H. Park, S. Yang, S. Wi, and S. Kim, "Integrated analysis of the energy and economic efficiency of pcm as an indoor decoration element: application to an apartment building," Solar Energy, vol. 196, pp. 437-447, 2019.

[33] E. Solgi, S. Memarian, and G. N. Moud, "Financial viability of pcms in countries with low energy cost: a case study of different climates in Iran," Energy and Buildings, vol. 173, pp. 128-137, 2018.

[34] ASTM:D5334-14, Standard Test Method for Determination of Thermal Conductivity of Soil And Soft Rock by Thermal Needle Probe Procedure, vol. 04, no. November, pp. 6-13, 2016.

[35] R. Cheng, M. Pomianowski, X. Wang, P. Heiselberg, and Y. Zhang, "A new method to determine thermophysical properties of PCM-concrete brick," Applied Energy, vol. 112, pp. 988-998, 2013.

[36] J. P. Holman, Experimental Methods for Engineers, McGrawHill Companies, New York, NY, USA, 2012.

[37] X. Sun, K. O. Lee, M. A. Medina, Y. Chu, and C. Li, “Melting temperature and enthalpy variations of phase change materials (PCMs): a differential scanning calorimetry (DSC) analysis," Phase Transitions, vol. 91, no. 6, pp. 667-680, 2018.

[38] D. Mazzeo, G. Oliveti, A. de Gracia, J. Coma, A. Solé, and L. F. Cabeza, "Experimental validation of the exact analytical solution to the steady periodic heat transfer problem in a PCM layer," Energy, vol. 140, pp. 1131-1147, 2017.

[39] S. Shaik and A. B. Talanki Puttaranga Setty, "Influence of ambient air relative humidity and temperature on thermal properties and unsteady thermal response characteristics of laterite wall houses," Building and Environment, vol. 99, pp. 170-183, 2016.

[40] CIBSE, CIBSE Environmental Design Guide A. The Chartered Institution of, Building Services Engineers London, London, UK, 2006.

[41] K. J. Kontoleon and D. K. Bikas, "The effect of south wall's outdoor absorption coefficient on time lag, decrement factor and temperature variations," Energy and Buildings, vol. 39, no. 9, pp. 1011-1018, 2007.
[42] S. Shaik and A. B. P. S. Talanki, "Optimizing the position of insulating materials in flat roofs exposed to sunshine to gain minimum heat into buildings under periodic heat transfer conditions," Environmental Science and Pollution Research, vol. 23, no. 10, pp. 9334-9344, 2016.

[43] G. M. Soret, P. Vacca, J. Tignard et al., "Thermal inertia as an integrative parameter for building performance," Journal of Building Engineering, vol. 33, Article ID 101623, 2020.

[44] ASHRAE, American Society Of Heating, Refrigerating and AirConditioning Engineers, Climatic Design Information, Atlanta, USA, Chapter 14, 2009.

[45] A. Bolattürk, "Optimum insulation thicknesses for building walls with respect to cooling and heating degree-hours in the warmest zone of Turkey," Building and Environment, vol. 43, no. 6, pp. 1055-1064, 2008.

[46] K. G. Kumar, S. Saboor, V. Kumar, K. H. Kim, and T. P. A. Babu, "Experimental and theoretical studies of various solar control window glasses for the reduction of cooling and heating loads in buildings across different climatic regions," Energy and Buildings, vol. 173, pp. 326-336, 2018.

[47] J. A. Duffie and W. A. Beckman, Solar Engineering of Thermal Processes, John Wiley and Sons, New York, NY, USA, 2013. 